\title{
Análise das publicações nacionais sobre educação à distância na enfermagem
}

\author{
Analysis of national publications about distance education in nursing \\ Análisis de las publicaciones nacionales acerca de la educación a la distancia en enfermería
}

\section{Alessandra Conceição Leite Funchal Camacho'}

'Universidade Estácio de Sá. Núcleo de Assistência de Enfermagem - Saúde do Adulto e Idoso. Rio de laneiro, RJ

Submissão: 03/05/2009

Aprovação: 16/07/2009

\section{RESUMO}

O objetivo é analisar as publicações Que trabalham a Educação à Distância na Enfermagem nas principais bases de dados de 2005 a 2009. Estudo de revisão de literatura sistemática realizada nas bases de dados da Biblioteca Virtual da Saúde (Lilacs, Scielo e Bdenf), no período de 19/02/09 à 24/04/09 em 20 referências analisadas. Destacam-se como tônica nas discussões: o desenvolvimento de cursos de capacitação para profissionais de enfermagem bem como em disciplinas nos cursos de graduação via Educação à Distância. Há uma evolução da Educação à Distância na Enfermagem com possibilidades de ensino no ambiente virtual de aprendizagem são inesgotáveis e levam em consideração alguns condicionantes relevantes para interatividade como a disponibilidade de cursos de capacitação e disciplinas nos cursos de graduação.

Descritores: Educação; Educação à Distância; Enfermagem.

\begin{abstract}
The objective is to examine the publications working in the Distance Education in nursing in the databases from 2005 to 2009 . Study of literature review conducted in the databases of the Virtual Health Library (Lilacs, Scielo and Bdenf) in the period from 19/02/09 to 24/04/09 in 20 selected references were reviewed. It is tonic in the discussions: the development of training courses for nurses and midwives as well as courses in graduate programs via Distance Education. There is an evolution of Distance Education in nursing with possibilities of teaching in virtual environment for learning is everlasting and take into account some constraints relevant to interactivity as the availability of training courses and disciplines in undergraduate courses.
\end{abstract}

Descriptors: Education; Education, distance; Nursing.

\section{RESUMEN}

El objetivo es examinar las publicaciones que trabajan la educación a distancia en enfermería en las principales bases de datos de 2005 a 2009. Estudio de revisión de literatura realizada en las bases de datos de la Biblioteca Virtual de Salud (Lilacs, Scielo y Bdenf) en el período comprendido entre 19/02/09 al 24/04/09 en 20 referencias. Es tónico en las discusiones: el desarrollo de cursos de capacitación para profisionales de enfermería, cursos en programas de postgrado a través de la educación a distancia. Hay una evolución en la educación a distancia de enfermería con posibilidades de enseñanza en el ambiente virtual de aprendizaje es inagotable y tenen algunas condiciones pertinentes para interactividad como la disponibilidad de cursos de formación y disciplinas de graduación.

Descriptores: Educación; Educación a Distancia; Enfermería. 


\section{INTRODUÇÃO}

A educação à distância na Enfermagem tem sido desenvolvida $\mathrm{e}$ utilizada em cursos de graduação de enfermagem e em diversas áreas de capacitação dos profissionais de enfermagem. Entendemos essa nova dinâmica de ensino como relevante porque permite Que o indivíduo seja capacitado e se insira numa nova realidade virtual Que permite a interatividade e o conhecimento de novas tecnologias. No entanto, é de destaque que o desenvolvimento de pesquisas, publicações e discussões sobre o ensino à distância tem sido muito ínfimo na realidade brasileira.

Neste sentido, Que a educação à distância entra como diferencial. Agora temos em potência mídias interativas e aprendizagem colaborativa para além da auto-aprendizagem e da mídia de massa. Aprender com o outro mediado por tecnologias Que permitem de fato Que estes "outros" se encontrem. Não é o ambiente on-line Que define a educação à distância. $\mathrm{O}$ ambiente e as suas interfaces condicionam, mas não determinam. Tudo dependerá do movimento comunicacional e pedagógico dos sujeitos envolvidos (discentes e docentes). Além de acreditarmos que só aprendemos porque o outro colabora com sua provocação, sua inteligência, sua experiência, sabemos Que temos interfaces Que garantirão a nossa comunicação com nossa fala livre e plural ${ }^{(1)}$.

Não podemos ignorar Que o uso de tecnologias em circunstâncias específicas para o ensino e educação na formação profissional de enfermeiros têm sido uma tônica atualmente. $\mathrm{O}$ Que leva a afirmar Que este tipo de formação é particularmente relevante Quando planejado e conduzido com intervenções específicas no ambiente organizacional de trabalho visando à capacitação de profissionais baseado na dimensão da aprendizagem e a troca de conhecimentos. $\mathrm{O}$ Que vemos nas instituições de ensino superior tanto no âmbito público Quanto privado realizando e desenvolvendo esforços no sentido de inserir profissionais de enfermagem capacitados no campo digital visando melhor resolução das ações interativas e articuladas seja na assistência de enfermagem através dos registros em prontuários eletrônicos, bem como, no desenvolvimento de disciplinas on-line nas estruturas curriculares e também em cursos de extensão ${ }^{(2)}$.

Existem Questões incontestáveis diante das transformações sócioculturais Que transcendem as fronteiras geográficas e econômicas. O cidadão torna-se consumidor compulsivo da informação audiovisual enquanto o conhecimento dilui-se em opiniões relativistas. Os valores culturais equivalem aos apelos publicitários Que se impõem como verdadeiras verdades na força sedutora das imagens. Tudo isso é desafio enorme para os educadores Que se encontram inquietos com a interrogação: como educar a geração pós-moderna ${ }^{(3)}$ ? É neste sentido com o uso das novas tecnologias para educação à distância torna-se possível concatenar conhecimentos norteadores de uma prática profissional engajada no mercado de trabalho.

A interatividade e as suas interfaces no ensino à distância é a palavra chave Que nos permite entender a importância desta modalidade de ensino na Enfermagem. A interatividade na cibercultura ocorre à transição da lógica da distribuição (transmissão) para a lógica da comunicação (interatividade). Isso significa modificação radical no esQuema clássico da informação baseado na ligação unilateral emissor-mensagem-receptor: a) o emissor não emite mais no sentido Que se entende habitualmente, uma mensagem fechada, oferece um leque de elementos e possibilidades à manipulação do receptor; b) a mensagem não é mais "emitida", não é mais um mundo fechado, paralisado, imutável, intocável, sagrado, é um mundo aberto, modificável na medida em Que responde às solicitações daquele Que a consulta; c) o receptor não está mais em posição de recepção clássica, é convidado à livre criação, e a mensagem ganha sentido sob sua intervenção ${ }^{(4)}$.

Na perspectiva da interatividade, o professor pode deixar de ser um transmissor de saberes para converter-se em formulador de problemas, provocador de interrogações, coordenador de equipes de trabalho, sistematizador de experiências, e memória viva de uma educação Que, em lugar de prender-se à transmissão, valoriza e possibilita o diálogo e a colaboração. Os fundamentos da interatividade podem ser encontrados em sua complexidade nas disposições da mídia on-line ${ }^{(4)}$.

A regulamentação da educação à distância está pautada Lei 9.394 (5) , de 20 de dezembro de 1996, autorizando, em seu Artigo 80, a Educação a Distância (EAD) como modo de ensino. Temos ainda a Portaria $4.059^{(6)}$ de 10 de dezembro de 2004, Que autoriza a introdução de disciplinas semi-presenciais em até $20 \%$ da carga horária total de cursos superiores reconhecidos, bem como a Portaria $4.36 \mathrm{I}^{(7)}$, de 29 de dezembro de 2004 Que regulamenta o processo de credenciamento de instituições de ensino para o uso regular da Educação à Distância em seus processos. A Lei de Diretrizes e Bases no Decreto 5.622 $2^{(8)}$, de 19 de dezembro de 2005, Que regulamenta no Artigo 80 a política oficial de educação à distância no país.

Portanto, o objetivo deste artigo é analisar as publicações que enfocam a educação à distância na Enfermagem através de referências nas principais bases de dados de 2005 a 2009.

\section{MÉTODO}

Para viabilizar o desenvolvimento deste estudo, foi desenvolvido um estudo de revisão de literatura sistemática. O período de coleta de dados se desenvolveu de 19/02/09 à 24/04/09 nas seguintes bases de dados da Biblioteca virtual da Saúde: Lilacs (Literatura Latino Americana e do Caribe em Ciências da Saúde), Scielo (Scientific Eletronic Library Online) e Bdenf (Base de Dados da Enfermagem).

O diferencial das revisões sistemáticas baseiam-se em uma metodologia rigorosa, principalmente numa busca de informações, utilizando-se de fontes de dados e numa avaliação da Qualidade dos estudos primários. Portanto, a revisão sistemática é o delineamento de um estudo secundário através de outros estudos, ditos primários, Que são analisados de forma criteriosa e avaliados Quanto à sua Qualidade científica para serem incluídos, ou não, numa análise estatística ${ }^{(9)}$.

Foram utilizados os seguintes descritores: Educação; Educação à Distância; Enfermagem.

Como Critérios de Inclusão as referências devem: Possuir aderência ao objetivo proposto; conter articulação com a educação à distância na Enfermagem. A análise das referências foi baseada nas publicações dos últimos 05 anos (de 2005 a 2009) em virtude do grande avanço da educação à distância no ensino na Enfermagem tanto em cursos de extensão como nos próprios cursos de graduação. 
Foi realizada a leitura superficial inicial das referências e, portanto, foram encontradas 15 referências Que pertencem a Lilacs; 12 referências pertencem a Scielo e 06 referências pertencem a Bdenf. Destaca-se que 03 referências se repetiram na Lilacs, Scielo e Bdenf; 03 referências se repetiram na Scielo e Lilacs e 03 referências se repetiram na Lilacs e Bdenf. Além disso, 5 referências somente foram encontradas na Lilacs; 06 referências somente foram encontradas na Scielo e nenhuma foi encontrada especificamente na Bdenf. Portanto, as referências Que serão analisadas perfazem um total de 20.

Para análise das informações foi realizada a organização do conteúdo encontrado Quanto ao ano, tipo de publicação e abordagem metodológica, essência do conteúdo/produção do conhecimento e recomendações dos autores.

\section{RESULTADOS E DISCUSSÃO}

Sobre o Quantitativo das referências por ano foi encontrado $10 \%$ das referências no ano de 2009; 30\% das referências no ano de 2008; 25\% das referências no ano de 2007; 25\% das referências no ano de 2006 e 10\% de referências no ano de 2005.

Este demonstrativo já nos leva a afirmar Que no período de 2005 a 2009 ocorreu um avanço nos estudos referentes à educação à distância na área da Enfermagem levando em consideração as tecnologias utilizadas e o seu conteúdo.

Ao analisar o tipo de publicação no Que tange as abordagens metodológicas utilizadas encontramos $15 \%$ das referências Que tratam de relatos de experiência; $5 \%$ das referências trabalham a abordagem instrucional; 10\% das referências desenvolveram seus estudos em aprendizagem baseadas em casos a; 20\% das referências realizaram estudos exploratórios descritivos; $5 \%$ das referências aplicaram a pes@uisa à avaliação centrada na teoria de engajamento; $5 \%$ das referências desenvolveram a avaliação de competências profissionais na perspectiva crítica e emancipatória em seus estudos; $5 \%$ tratava-se de um editorial sobre a educação à distância; 5\% das referências realizaram um estudo experimental randomizado; $10 \%$ das referências trataram da análise de conteúdo com abordagem Qualitativa; $5 \%$ das referências utilizaram o modelo teórico de Tronchim para construção de web sites; $5 \%$ das referências desenvolveram pesQuisa bibliográfica; $5 \%$ das referências realizaram estudos Quanti-Qualitativos e 5\% das referências desenvolveram a avaliação diagnóstica, processual e somativa em seu estudo.

Grande parte destas referências estiveram voltadas para aplicação de modelos específicos de avaliação e de desenvolvimento para as web aulas visando a interatividade e participação contínua dos discentes participantes e de especialistas.

Sobre a essência do conteúdo estudado nas referências e as suas produções no conhecimento há $25 \%$ dos estudos sobre a educação à distância sendo desenvolvidas nos cursos de graduação em Enfermagem no Brasil com as seguintes abordagens de ensino: na disciplina de Legislação, Ética e Exercício de Enfermagem; na disciplina de Fundamentos de Enfermagem com ênfase na Administração de Medicamentos e na disciplina de Saúde mental através de estudo de casos clínicos de pacientes com distúrbios mentais.

Diante destes achados pode-se examinar o mundo de hoje com ferramentas de ontem; mas é muito melhor tentar construir novas ferramentas para pensá-lo e examiná-lo (o mundo de hoje) a partir de novas bases que tragam a reflexão. Essa reflexão pode permitir a construção de possibilidades educacionais Que acabam desmistificando nossas crenças anteriores e nos permitindo crescer não mais como meros espectadores mas, como àQueles Que estão no processo de construção contínua do conhecimento digital na Enfermagem $^{(2)}$.

Há uma percepção Que os cursos de graduação em Enfermagem estão adotando didáticas e temas inovadores na área da enfermagem através do ensino à distância permitindo Que os estudantes de graduação tenham também o acesso a novas tecnologias e se tornem incluídos digitais.

Dando continuidade sobre a essência do conteúdo estudado nas referências e as suas produções no conhecimento, há 35\% dos estudos centrados em cursos de capacitação para profissionais de enfermagem via educação à distância. Verificamos abordagens de capacitação diversas como: curso sobre pacientes com transtorno depressivo; curso sobre drogas; curso sobre cardioversão; curso sobre esterilização de materiais; curso sobre tratamento de feridas; curso de atualização para auxiliares de enfermagem e curso sobre o pé diabético.

Paralelamente, há Que se considerar outro fator importante, vivemos em um país de dimensões continentais, e a missão de levar a formação adequada a todos os profissionais do Sistema Único de Saúde (SUS), pelos meios tradicionais, torna-se uma missão cara e de difícil realização. Uma das respostas para transpor este impasse é a educação à distância. Entretanto, não deve ser vista como substitutiva de outras formas de educação convencional, mas como modalidade educacional alternativa Que visa atuar de forma significativa no ensino à distância na Enfermagem ${ }^{(10)}$.

As propostas destes cursos de capacitação para os profissionais de enfermagem via educação à distância são inovadoras e abordam temas relevantes levando o profissional de enfermagem a refletir e discutir a sua prática profissional bem como a se atualizar e se inserindo num mercado de trabalho Que, a cada momento, engloba novas tecnologias para o desenvolvimento destes profissionais.

Verifica-se que 10\% dos estudos apontam a formação pedagógica dos tutores on-line na Enfermagem como relevante levando em consideração suas experiências. Foi encontrado em 15\% das referências Que a educação on-line possui um importante papel nos cursos de pós-graduação lato sensu levando em consideração a disponibilidade de novas tecnologias acessíveis via on-line para o ensino à distância.

A função orientadora do tutor se apóia nos processos de integralidade - orientação dirigida a todas as dimensões da pessoa; universalidade - orientação dirigida a todos os orientandos; continuidade - orientação durante todo o processo de ensinoaprendizagem; oportunidade - orientação nos momentos críticos da aprendizagem; e participação - todos os tutores devem participar do processo de aprendizagem do aluno matriculado em mais de uma disciplina na mesma instituição(11).

Ocorreram cerca de $5 \%$ das referências Que tratavam de revisão bibliográfica centrada na Educação à Distância no Brasil levando em consideração a utilização dos recursos disponíveis no ambiente virtual de aprendizagem.

Diante desses achados a área de Educação em Enfermagem é a Que mais tem utilizado os recursos do sistema Internet. Apresenta 
diversas modalidades, destacando-se as aplicações voltadas para o ensino on-line. Temos ainda as áreas de Educação do Paciente (área bastante desenvolvida cujo destaque é o papel do enfermeiro como provedor de informação de saúde, enfocando o aspecto da prevenção de doenças e suporte a grupos de pacientes específicos); a área de Assistência (é a Que apresenta modalidades ou aplicações Que enfocam a representação do conhecimento de enfermagem, algo útil para providenciar a prática baseada em evidências) e, por fim há a área de Pesquisa em Enfermagem (relatou menor número de modalidades de utilização, sendo destaque a pesquisa bibliográfica e a coleta de dados on-line) ${ }^{(12)}$.

Além disso, foram encontrados em $5 \%$ das referências estudos traçando um comparativo sobre a mesma disciplina sendo ministrada via presencial e on-line. Destaca-se que neste último os resultados foram semelhantes confirmando o ensino à distância como compatível e eficaz.

A educação à distância no foco corporativo com a aplicação de tecnologia da informação e comunicação Que visa apoiar o desenvolvimento profissional contínuo, com promoção do aprendizado colaborativo em grupos geograficamente separados, é denominado de e-learning Que é uma modalidade de ensino à distância Que possibilita a auto-aprendizagem, com a mediação de recursos didáticos, sistematicamente, organizados, apresentados em diferentes suportes tecnológicos de informação, utilizados de modo isolado ou combinado, e veiculados pela Internet ${ }^{(13)}$.

Em cerca de 5\% das referências foi destacado o desenvolvimento da Educação à Distância no Brasil.

No entanto, no Que tange sobre as recomendações dos autores 10\% das referências trazem duas recomendações: a primeira está centrada no estabelecimento do desenvolvimento de estratégias de ensino articuladas com o conteúdo programático da disciplina através das ferramentas disponíveis no ambiente virtual visando desenvolvimento crítico e reflexivo do futuro profissional enfermeiro em Que o ensino deve sempre ser centrado no aluno. É uma atividade de incentivo contínuo ao estudante de enfermagem considerando suas perspectivas no sentido de desenvolver sua capacidade de decisão nas atividades propostas.

Ocorreram 10\% das referências referem Que o material produzido para educação à distância deverá atender a necessidade de formação e/ou atualização dos profissionais de Enfermagem, acadêmicos de Enfermagem e de outros profissionais de saúde no Que se refere ao atendimento ao paciente, à sua família e à comunidade. Além disso, os resultados reforçam a rieueza da discussão para a aprendizagem do estudante e evidenciam a potencialidade do uso de recursos tecnológicos, como as ferramentas de comunicação em tempo real, para apoiar e incrementar as possibilidades educativas em enfermagem.

Neste sentido na área da saúde o uso da Internet busca a oportunidade de utilizar a Web e obter meios de aperfeiçoamento profissional constante e de Qualidade através do acesso a sites de universidades e revistas científicas, além de poder entrar em contato com outros profissionais para troca de informações e da realização de cursos à distância, se tornou condição fundamental para capacitação de pessoal ${ }^{(14)}$.

Há 15\% das referências Que evidenciam o ambiente colaborativo e interativo possui relevância no processo de ensino-aprendizagem discente. Além disso, contribuem afirmando que os dados obtidos e as análises realizadas, sugerem um impacto significativo com o desenvolvimento do curso de Especialização em Enfermagem no desenvolvimento da competência em problematizar a realidade dos serviços de saúde em Que atua, face ao Sistema único de Saúde.

Entendemos que a competência de problematizar a realidade do serviço da saúde em Que atua em relação ao Sistema Único de Saúde, justifica-se por considerar Que a prática da Enfermagem brasileira não pode ser compreendida separadamente do contexto social e político do país, em especial no Que diz respeito à saúde. As políticas de saúde apresentam-se como uma maneira da sociedade se organizar para tratar a Questão da saúde de seus membros, pois estruturam-se como um ato de comunicação, uma vez Que independente do local onde o enfermeiro trabalha e, por mais Que lhe pareça estar longe das Questões e das decisões políticas, tais políticas fazem parte e interferem na prática da Enfermagem. De fato, neste ínterim a educação à distância entra como possibilidade de interatividade e de discussão de conhecimentos sobre as políticas públicas de saúde ${ }^{(15)}$.

Em 25\% das referências apontam Que é necessário Que as instituições de ensino de Saúde adotem políticas de investimento na capacitação tecnológica docente e discente, bem como na implementação de infra-estrutura para o desenvolvimento de projetos de educação à distância estruturados em propostas pedagógicas Que viabilizem a construção de competências, habilidades e conhecimento nas áreas de tecnologia da informação e de educação utilizando novas estratégias de ensino. Esta modalidade de ensino pode ser considerada como uma experiência inicial Que após revisão e aprimoramento, poderá ser replicada de forma a atingir um público mais amplo. Acredita-se Que a educação à distância com o uso da Internet pode colaborar para a educação permanente, pois num país com carências educacionais tão grandes como o nosso, o acesso facilitado da educação à distância, pode eliminar barreiras geográficas e, gradualmente, promover educação com Qualidade. A modalidade educação à distância pode se constituir ferramenta adequada para eualificar os profissionais da enfermagem Que, por algum motivo, não têm acesso a cursos de aperfeiçoamento.

Neste sentido, vislumbra-se a possibilidade de contribuição para o saber transformador, destacando a educação à distância como uma rica possibilidade para o incremento na formação e capacitação do profissional de enfermagem, através de um processo educativo no Qual a aprendizagem é realizada com separação física entre alunos e professores. $\mathrm{O}$ aprendizado e a comunicação acontecem por meio de recursos tecnológicos Que ultrapassam a exposição oral ${ }^{(16)}$.

Em 20\% das referências há necessidade dos materiais educacionais possuírem características como interatividade reintegração, pois possibilitam o controle e a interdependência do aluno na seleção das informações e no seu ritmo do trabalho, atendendo aos variados estilos e preferências de aprendizagem, oferecendo alternativas de navegar pelo programa por meio de associações de conceitos e a descoberta de interconexões necessária para compreensão do conteúdo estudado, além de um instrumento importante para educação permanente. O processo de educação permanente em enfermagem representa um grande impacto na melhoria da gestão do conhecimento, da Qualidade da assistência e da satisfação do atendimento ao cliente.

A formação pedagógica proposta para os professores concebe a educação, assim como a saúde, como práticas Que integram o 
sistema social, no conjunto das demais práticas da nossa sociedade. Esta concepção de educação propõe uma abordagem reflexiva e crítica dos conteúdos, a partir da realidade, do contexto em que as práticas de educação e saúde se desenvolvem ${ }^{(17)}$. É nesta proposta Que a educação à distância visa proporcionar um tutor Que reflete sua prática constantemente até porque a prática docente on-line assim como a presencial se constrói continuamente.

Em 5\% das referências propõem algumas ações futuras tais como: o conteúdo deste web site deverá ser atualizado periodicamente, sendo acrescentadas novas informações pertinentes ao assunto e ou substituídas às consideradas obsoletas; devem incluir um grupo de discussão virtual, no eual os enfermeiros e interessados no assunto possam trocar experiências e conteúdos a respeito do tema; devem despertar em outros enfermeiros o interesse para desenvolver web sites com novos temas, visando com isto, à formação de mais profissionais especialistas na área e o aperfeiçoamento do conhecimento em tecnologia da informação em enfermagem.

Entende-se que o avanço tecnológico, a globalização e a mudança exigida das pessoas no ambiente de trabalho determinam uma nova postura profissional do enfermeiro. Mais do que conhecimento, ele precisa de atualização constante, por meio da sua educação permanente e a informática é uma ferramenta imprescindível para facilitar esta aprendizagem em QualQuer ambiente, no trabalho ou fora dele. Sendo assim, é imprescindível que o enfermeiro domine esta área de conhecimento e a aprimore, contribuindo para a divulgação científica de práticas inovadoras para a enfermagem ${ }^{(18)}$. A modalidade educação à distância pode constituir uma ferramenta adequada para Qualificar os profissionais da enfermagem Que, por algum motivo, não têm acesso a cursos de aperfeiçoamento ${ }^{(19)}$.

Foi evidenciado Que em 10\% das referências apontam o Quão positiva foi a união entre a educação à distância e os recursos tecnológicos. Além disso, destacam que a enfermagem vem utilizando satisfatoriamente os recursos do sistema Internet e, isto tem contribuído para o próprio desenvolvimento da profissão.

Ainda como contribuição dos autores verifica-se Que em 5\% das referências os tutores on-line consideraram um desafio desempenhar a tutoria, por ser uma experiência nova para a Qual não há modelo predefinido a seguir. Os resultados indicaram Que a educação à distância ainda não foi culturalmente assimilada pelos tutores e Que superar a distância pode ser ainda mais difícil para profissionais de enfermagem Que possuem dupla jornada de trabalho.

Estes estudos demonstram Que as estratégias de ensino utilizadas nas instituições são embasadas por políticas Que são incorporadas como uma realidade prática na formação de profissionais de enfermagem através da educação permanente ${ }^{(20)}$. Portanto, o Que vemos é um claro sinal da evolução da educação à distância na Enfermagem no Brasil em Que as possibilidades de ensino no ambiente virtual de aprendizagem são inesgotáveis e levam em consideração alguns condicionantes relevantes para interatividade como a disponibilidade de cursos de capacitação e disciplinas nos cursos de graduação. Leva-se em consideração suas interfaces através da atualização constante de conteúdos bem como a disponibilidade de textos, links e vídeos que corroboram com o processo de aprendizagem.

\section{CONCLUSÃO}

É importante a realização de novos estudos com o objetivo de desenvolver ou aprimorar novos métodos de ensino, aprendizagem e de avaliação dos alunos nos cursos de capacitação profissional e de graduação em enfermagem Que envolvem a Educação à Distância na Enfermagem.

Este estudo tem oferecido um Quantitativo de informações relacionadas ao ensino da educação à distância na enfermagem através de tecnologias de informática modernas provendo estratégias importantes de acesso ao ambiente virtual de aprendizagem permitindo a capacitação de profissionais de enfermagem através de tutores Que incentivam a interatividade como processo contínuo de aprendizagem.

Em geral as tecnologias da educação constituem um crescente recurso Que fornece suporte no processo de aprendizagem. A mais importante característica deste recurso é considerar um trabalho pedagógico com diferentes referencias de ensino. Neste sentido, entendo que o presente estudo atendeu o seu objetivo a partir do momento Que evidenciou o desenvolvimento da educação à distância na enfermagem através de estudos fidedignos.

\section{REFERÊNCIAS}

1. Santos E. Diferença entre EAD e Educação Online: depoimento de uma pesquisadora. Rio de Janeiro: UERJ, 2008.

2. Camacho, ACLF. Relato de experiência na educação on-line na disciplina de legislação, ética e exercício de enfermagem. Rev Bras Enferm 2009; 62 (1):15 I-5.

3. Marfra L, Tura M. Sociologia para educadores 2: o debate sociológico da educação no século XX e as perspectivas atuais. In: Silva M. Educar em nosso tempo: desafio da teoria social pós-moderna. Rio de Janeiro: Quartet; 2005.

4. Silva M. Internet na educação e inclusão social na era digital, na sociedade da informação e na cibercultura. Rio de Janeiro: EdUERJ; 2008.

5. Ministério da Educação (BR). Lei 9.394 de 20 de Dezembro de 1996. Brasília: Ministério da Educação; 1996.

6. Ministério da Educação (BR). Portaria 4.059, de 10 de Dezembro de 2004. Brasília: Ministério da Educação; 2004.

7. Ministério da Educação (BR). Portaria 4.361, de 29 de Dezembro de 2004. Brasília: Ministério da Educação; 2004.

8 Ministério da Educação (BR). Decreto 5.622, de 19 de Dezembro de 2005. Brasília: Ministério da Educação; 2005.

9 Bork AMT. Enfermagem Baseada em evidências. Rio de Janeiro: Guanabara Koogan; 2005.

10 Candido MCFS, Furegato ARF. Transtornos depressivos: um material didático para educação à distância. Esc Anna Nery Rev Enferm 2008; 12 (3): 473-8.

I I Barbosa MFSO, Rezende F. A prática dos tutores em um programa de formação pedagógica à distância. Interface Comunic., Saúde, Educ. 2006; 10 (20):473-86.

12 Santos SGF, Marques IR. Uso dos recursos de Internet na Enfermagem: uma revisão. Rev Bras Enferm 2006; 59(2): 212-6. 
13 Paladino Y, Peres HHC. E-learning: a comparative study for knowledge apprehension among nurses. Rev Latino-am Enfermagem 2007; 15(3): 397-403.

14 Rodrigues RCV, Peres HHC. Panorama brasileiro do ensino de Enfermagem On-line. Rev Esc Enferm USP 2008; 42(2): 298-304.

15 Backes VMS, Martins ST, Ferraz F, Schmidt SMS, Prado ML,
Lino MM, et al. Competência dos Enfermeiros em problematizar a realidade do serviço de saúde no contexto do Sistema único de Saúde. Texto Contexto Enferm 2007; 16(4): 727-36.

16 Telles Filho PCP, Cassiani SHDB. Ciclo de criação e avaliação do módulo administração de medicamentos para ensino à distância. Rev Latino-am Enfermagem 2008; I6(1): 78-85. 